\title{
A survey on COVID-19 vaccine acceptance and concern among Malaysians
}

\author{
S. A. R. Syed Alwi", E. Rafidah, A. Zurraini, O. Juslina, I. B. Brohi and S. Lukas
}

\begin{abstract}
Background: Vaccination is an effective way to curtail the burden of COVID-19 in which success depends on a high acceptance of the vaccine. However, addressing concerns among vaccine-hesitant individuals is essential to avoid failure of the immunisation programme. This study sought to assess the concerns and acceptance rates regarding the COVID-19 vaccine among Malaysians.

Methods: An online questionnaire was distributed to 1411 respondents via a snowball sampling method among Malaysians aged 18 years and above.

Results: The majority of the respondents were young adults (40.7\%), female (62.8\%), Malay (63.8\%), Muslim (72.3\%), married (52.9\%), with tertiary education (86.8\%) and without medical illness (85\%). Social media (97.4\%) was the primary source of information regarding COVID-19. The overall acceptance rate was high (83.3\%), with the lowest rates among the elderly aged 60 years and above (63.4\%) and pensioners (64.6\%). Hesitance was caused by concerns regarding side effects (95.8\%), safety (84.7\%), lack of information (80.9\%), effectiveness (63.6\%) and religious (20.8\%) and cultural factors related to the COVID-19 vaccine (6.8\%). Respondents with diabetes mellitus (24.7\%) and hypercholesterolemia (23\%) were more hesitant to accept the COVID-19 vaccine, at 16.1 and 15.8\%, respectively. Predictors of COVID-19 vaccine hesitance were age, religion, and current residence.

Conclusions: The results indicate a high rate of acceptance of the COVID-19 vaccine among Malaysians. Thus, the Malaysian government and other related agencies should increase their campaign and prepare to implement the COVID-19 mass immunisation programme among Malaysians. However, despite the high acceptance rate, it remains important to address concerns among hesitant individuals by building trust in vaccine safety and effectiveness through adequate information regarding the vaccine.
\end{abstract}

Keywords: COVID-19, Vaccine, Acceptance, Concern

\section{Background}

The COVID-19 pandemic caused by severe acute respiratory syndrome coronavirus 2 (SARS-CoV-2) has infected more than 108 million people in over 150 countries. In Malaysia, as of February 15, 2021, more than 261,805 confirmed cases with 958 deaths had been reported $[1,2]$. The pandemic continues to threaten the healthcare system with catastrophic

\footnotetext{
* Correspondence: sarsalwi@unimas.my

Department of Family Medicine, Faculty of Medicine and Health Sciences,

Universiti Malaysia Sarawak, 94300 Kota Samarahan, Sarawak, Malaysia
}

economic, education, and social consequences worldwide $[3,4]$.

Currently, no curative treatment exists for COVID-19 infection [5-7]. Therefore, a safe and effective prophylactic vaccine is urgently needed to contain the pandemic, which has had devastating medical, economic, and social repercussions [8]. To date, several vaccines have been developed and approved for emergency immunisation [9-11]. This has given a glimpse of hope for preventing the spread of COVID-19 infection. Countries and governments worldwide have spent billions of dollars in preparing to immunise the population of their

(C) The Author(s). 2021 Open Access This article is licensed under a Creative Commons Attribution 4.0 International License, which permits use, sharing, adaptation, distribution and reproduction in any medium or format, as long as you give appropriate credit to the original author(s) and the source, provide a link to the Creative Commons licence, and indicate if changes were made. The images or other third party material in this article are included in the article's Creative Commons licence, unless indicated otherwise in a credit line to the material. If material is not included in the article's Creative Commons licence and your intended use is not permitted by statutory regulation or exceeds the permitted use, you will need to obtain permission directly from the copyright holder. To view a copy of this licence, visit http://creativecommons.org/licenses/by/4.0/ The Creative Commons Public Domain Dedication waiver (http://creativecommons.org/publicdomain/zero/1.0/) applies to the data made available in this article, unless otherwise stated in a credit line to the data. 
countries. In Malaysia, the government has announced an initial purchase of vaccines amounting to RM 3 billion [12].

Vaccination programmes can lead to herd immunity without requiring a substantial proportion of the community to be infected. However, such immunity requires a sufficient proportion of the population to be vaccinated. While vaccination is effectively recognised as an effective way to reduce and eliminate the burden of COVID-19, its effectiveness depends on the population's willingness to be vaccinated. Immunisation programmes are only successful when there is a high acceptance rate of the vaccine [13-16].

Studies from other countries have identified many factors that influence the acceptance of the COVID-19 vaccine. These include risk perception of the disease, perception of vaccine safety and efficacy, general vaccination attitudes. Past vaccination history, doctors' recommendation, vaccination costs, vaccination convenience and sociodemographic characteristics [16, 17]. Governments, public health officials and advocacy groups must be prepared to address hesitancy and built vaccine literacy so the public will accept immunisation when appropriate [14].

A few studies have explored the acceptance rates and determinants of the COVID-19 vaccine. One study conducted among healthcare workers $(\mathrm{HCW})$ in China showed high acceptance of the vaccine as compared to the general population. Studies conducted in Saudi Arabia, Indonesia, the European Union, and the United States among the general population showed a high degree of acceptance of the COVID-19 vaccine. However, another study conducted by Decanar Ajumbo et al. (2020) among Western Ugandans showed only average acceptance of the COVID-19 vaccine among the general population [15-19].

This study sought to assess the acceptance of the COVID-19 vaccine among the general population of Malaysia. Understanding the perspectives of the population is critical for the government and relevant agencies so they may formulate the best approach to implement the COVID-19 vaccination programme in Malaysia.

\section{Methods}

This cross-sectional study was conducted from December 23-29, 2020, after approval from the Research and Ethics Committee, Faculty of Medicine and Health Sciences, Universiti Malaysia Sarawak (approval reference: NO RUJUKAN ETIKA FME/21/40). All research methods were performed in accordance with the relevant guidelines and regulations of the Declaration of Helsinki. The target participants were Malaysian adults aged 18 years and above who could read and understand Bahasa Malaysia or English. Due to the limitations in employing face-to-face methods during an active outbreak, the data were collected using the Google Forms platform via an online questionnaire. A snowball sampling strategy was used to distribute the online questionnaire via social media (WhatsApp, Facebook, Twitter). First, 50 primary recipients were recruited. These participants were then asked to share the questionnaire link to individuals in their social circles (aged 18 years and above). These social media platforms were chosen because they are widely used among the Malaysian population across sociodemographic characteristics.

The minimum sample size was calculated using OpenEpi Version 3. In 2019, the Malaysian population of adults aged 18 years and above was around 21.8 million [20]. The minimum sample size calculated with a $95 \%$ confidence interval was 384 . A total of 1411 completed responses were collected.

\section{Questionnaire on COVID-19 vaccine: acceptance and concerns}

The questionnaire was developed via expert group discussion and literature reviews [15-18]. The survey form consisted of 14 questions covering sociodemographic characteristics (Questions 1 to 10), medical illnesses (Question 11), source of information regarding COVID19 (Question 12), acceptance of COVID-19 vaccine (Question 13) and concerns regarding the COVID-19 vaccine (Question 14). All respondents were required to answer Questions 1-13. Question 14 was only answered by respondents who responded 'no' to Question 13.

Sociodemographic characteristics (Questions 1-10) included current residency, place of birth, age in years, gender, race, religion, marital status, education level, occupation and monthly income. Medical illnesses (Question 11) included diabetes, hypertension, hypercholesterolemia, respiratory disease, renal disease, heart disease and cancer. Source of information regarding COVID-19 (Question 12) included social media, mass media, HCWs and friends/family/neighbour. Question 14 addressed the concerns regarding the COVID-19 vaccine, such as a lack of information regarding the vaccine, side effects, safety, effectiveness, COVID-19 is not dangerous, fear of injection, against vaccination in general, religious reasons, cultural reasons and belief in traditional remedies. For Questions 11, 12, and 14, respondents could choose more than one answer but only one answer for Question 13. The answer responses for Questions 11, 12, 13 and 14 were in dichotomous 'yes' or 'no' format.

The original questionnaire was developed in English and later translated to Bahasa Malaysia using forward and back translation. A pilot study was conducted among the general population through snowball sampling of 76 individuals, $20 \%$ of the total calculated 
sample size of 384 , to ensure the questions were clearly written, easily understood and unambiguous. A reliability test was conducted for Question 14 to determine the internal consistency of 10 items listed measuring COVID-19 vaccine concerns, resulting in a Cronbach's alpha of 0.6 .

\section{Data analysis}

Data analysis was done using the Statistical Package for Social Science version 22.0. Descriptive analyses were used for sociodemographic and categorical data. The variables associated with COVID-19 vaccine acceptance and hesitancy were analysed using bivariate analysis. Further analyses were conducted to identify predictors of COVID-19 vaccine hesitancy using multiple logistic regression. A $p$-value of less than .05 and a confidence interval of $95 \%$ was considered statistically significant.

Another analysis to determine significant concerns among hesitant respondents was performed using the Relative Importance Index (RII), as shown in Table 3. Ten items were listed to measure concerns among hesitant respondents with dichotomous responses of 'yes' or 'no'. A score of 2 was given to 'yes' responses and 1 to 'no' responses to calculate the RII for each item using the formula below:

$$
\begin{aligned}
& \mathrm{RII}=\Sigma \mathrm{W} /(\mathrm{A} * \mathrm{~N}) \\
& \mathrm{W}=\text { weighting for each item } \\
& \mathrm{A}=2(\text { the highest weight) } \\
& n=236 \text { (total number of hesitant respondents) }
\end{aligned}
$$

\section{Results}

A total of 1411 respondents participated in this study. Table 1 provides an overview of their sociodemographic characteristics. Almost half of the respondents (40.7\%) were young adults (18-29 years old), whereas the elderly aged 60 years and above were the minority $(5.8 \%)$. The majority of respondents were female (62.8\%), Malay (63.8\%), Muslim (72.3\%), married (52.9\%) and had tertiary education $(86.8 \%)$. Respondents came from various occupation sectors, including students (25.4\%), education (16.6\%), medical and health (15.6\%) and management and administrative (10\%). Other occupations such as services (8.4\%), industrial and manufacturing (4.5\%), security and defence (2.2\%), construction $(2.2 \%)$, other occupation (2\%), pensioner (5.8\%) and unemployed (7\%) contributed to the minority group. About one third of the respondents were in the lowest monthly income category of RM 0-1200 (35.5\%), followed by RM 12014000 (25.2\%) and RM 4000-8000 (25.1\%). Almost half of the respondents resided in Sarawak state (48.7\%).
More than $85 \%$ of the respondents reported having no known medical illness (Table 2). A small percentage of respondents had hypercholesterolaemia (13.3\%), hypertension $(12.8 \%)$, diabetes mellitus $(6.9 \%)$, respiratory disorder $(4 \%)$, heart disease $(2 \%)$, renal disorder $(1.3 \%)$ and cancer $(0.6 \%)$.

\section{Information regarding COVID-19 and COVID-19 vaccine hesitancy}

Most respondents acquired information regarding COVID-19 through social media (97.4\%), mass media (94\%), friends and family (79.3\%) and HCWs (59.8\%) (Table 2). COVID-19 vaccine acceptance in Malaysia (83.3\%) was substantially higher than hesitance $(16.7 \%)$. Hesitant respondents reported they were concerned about the side effects (95.8\%), safety (84.7\%) and lack of information regarding the vaccine (80.9\%). Another concern by more than half of the respondents was the vaccine's effectiveness (63.6\%). Slightly more than one quarter were against vaccination in general (28\%), whereas slightly less than one quarter believed COVID19 is not dangerous (22.5\%). Minority groups were not willing to accept vaccination due to religious (20.8\%) and cultural $(6.8 \%)$ reasons, belief in traditional remedies (17.8\%) and fear of injection (16.1\%).

The RII for concerns regarding the COVID-19 vaccine among hesitant respondents indicated the most important concerns were side effects $(\mathrm{RII}=0.98)$, followed by safety $(R I I=0.92)$, lack of information $(R I I=0.90)$ and effectiveness $(\mathrm{RII}=0.82)$ of the vaccine (Table 3 ).

\section{Factors associated with COVID-19 vaccine hesitancy}

As shown in Table 4, sociodemographic factors significantly associated with COVID-19 vaccine hesitance were age $(p<.001)$, race $(p=.025)$, marital status $(p=.001)$, occupation $(p<.001)$, monthly income $(p=.044)$, current residence $(p=.018)$ and having diabetes $(p=.028)$ and hypercholesterolemia $(p=.014)$. COVID-19 vaccine hesitance was ignificantly different across age groups, with the highest hesitance seen among the oldest age group of 60 years and above (36.6\%). Among all races in Malaysia, a substantial proportion of COVID-19 vaccine hesitance was seen among Kadazan (30.4\%), Indian (27.9\%), Dusun (26.1\%), Orang Ulu (24.1\%) and other indigenous and non-Malaysian groups (22.6\%). Furthermore, respondents who were married or divorced were more hesitant to get the COVID-19 vaccine than single respondents (12.1\%) and widows/widowers (15\%). Pensioners $(35.4 \%)$ were the most hesitant to accept the COVID-19 vaccine across all occupations. Hesitance was highest among respondents with monthly incomes of RM 4000 and above.

The proportion of hesitance between respondents in different states in Malaysia was also significantly 
Table 1 Sociodemographic characteristics among respondents $(N=1411)$

Sociodemographic characteristics

Age (year)

18-29

30-39

40-49

50-59

60 and above

Gender

Male

Female

Race

Malay

Chinese

Indian

Iban

Bidayuh

Melanau

Orang Ulu

Kadazan

Dusun

Others

Religion

Islam

Christianity

Buddhism

Other

Marital status

Single

Married

Divorced

Widow/Widower

Education

Less than tertiary education

Tertiary education

Occupation

Medical \& Health

Education

Security \& Defence

Industrial \& Manufacturing

Construction

Management \& Administrative

Services

Student

Pensioner

Unemployed n

$\%$

574

341

24.2

246

17.4

168

11.9

82

5.8

886

62.8

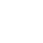

.7.

9

3

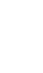

4

2

8

8

.

5

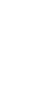

8

3

7


Table 1 Sociodemographic characteristics among respondents $(N=1411)$ (Continued)

\begin{tabular}{lll}
\hline Sociodemographic characteristics & $\boldsymbol{n}$ & \% \\
\hline Others & 33 & 2.4 \\
Monthly income (RM) & & \\
$0-1200$ & 501 & 35.5 \\
$1201-4000$ & 356 & 25.2 \\
$4001-8000$ & 354 & 25.2 \\
$>8000$ & 200 & 14.2 \\
Current residence & & \\
Sarawak & 687 & 48.7 \\
Sabah \& WP Labuan & 102 & 7.23 \\
Northern Zone* & 118 \\
Middle Zone* & 336 \\
Southern Zone* & 3.36 \\
East Coast Zone* & 117 \\
\hline
\end{tabular}

*Northern Zone: Kedah, Perak, Pulau Pinang, Perlis

*Middle Zone: Selangor, WP Kuala Lumpur, WP Putrajaya

*Southern Zone: Negeri Sembilan, Melaka, Johor

*East Coast Zone: Kelantan, Terengganu, Pahang

different $(p=.018)$. Respondents residing in the East Coast Zone of Peninsular Malaysia and Sabah \& WP Labuan had the highest proportion of hesitance (27.5 and $26.5 \%$, respectively). Respondents with diabetes mellitus (24.7\%) and hypercholesterolemia (23\%) were more hesitant to accept the COVID-19 vaccine than those without (16.1 and $15.8 \%$, respectively).

\section{Predictors of COVID-19 vaccine hesitance}

Further analysis using multiple logistic regression was performed to determine predictors of COVID-19 vaccine hesitance among respondents (Table 5). The model containing all 20 independent variables was statistically significant, ${ }^{2}=59.19 p<.001$. The model as a whole explained between $4 \%$ (Cox and Snell R Square) and 7\% (Nagelkerke $\mathrm{R}$ Square) of variance in COVID-19 vaccine hesitance and correctly classified $83.2 \%$ of the cases.

As shown in Table 5, only three variables made a statistically significant contribution to the model. The strongest predictor of COVID-19 vaccine hesitance was age. Respondents aged 60 years and above were five times more hesitant and respondents aged 30 to 59 years were two times more hesitant to take the COVID-19 vaccine when compared with the younger age group of 18 to 29 years after controlling for all other factors in the model. Other predictors of COVID-19 hesitance were religion and current residence. Individuals who reported following Buddhism and other religions were twice as hesitant to take the COVID-19 vaccine compared to those following Islam. Meanwhile, respondents from Sabah, WP Labuan, and the East Coast Zone in Peninsular Malaysia were twice more hesitant to take the COVID-19 vaccine than individuals residing in Sarawak.

\section{Discussion}

Vaccination is recognised as an effective way to reduce and eliminate the burden of COVID-19. However, the success of a vaccination programme depends on the willingness of the population to be vaccinated. This study used an online self-administered questionnaire and collected responses across Malaysia. Out of 1411 respondents, the acceptance rate of the COVID-19 vaccine in Malaysia was $83.3 \%$, much higher than the hesitance rate $(16.7 \%)$. This acceptance rate corresponds to studies conducted among the general population in Indonesia, China, Europe and Saudi Arabia [15-18].

For this study, age, race, marital status, current residence, monthly income, occupation and medical condition (diabetes mellitus and hypercholesterolaemia) significantly influenced vaccine acceptance $(p<.05)$ (Table 4). In contrast, studies in China and Saudi Arabia only showed gender and marital status as significantly influencing vaccine acceptance $[16,18]$. Studies from Indonesia did not show any significant association between sociodemographic characteristics and vaccine acceptance, except being an HCW [15]. The difference between these findings might be due to different methodology and sociodemographic characteristics among the participants in the study.

Further analysis using multiple logistic regression identified significant predictors for COVID-19 vaccine hesitancy, including age, religion and current residence. Respondents aged 60 years and above were five times more hesitant to take the vaccine, followed by 
Table 2 Medical illnesses, source of information, acceptance and concerns regarding COVID-19 vaccine among respondents ( $N=$ 1411)

\begin{tabular}{|c|c|c|c|}
\hline \multicolumn{2}{|l|}{ Medical illnesses } & \multirow{2}{*}{$\begin{array}{l}\boldsymbol{n} \\
97\end{array}$} & \multirow{2}{*}{$\frac{\%}{6.9}$} \\
\hline Diabetes mellitus & Yes & & \\
\hline & No & 1314 & 93.1 \\
\hline \multirow[t]{2}{*}{ Hypertension } & Yes & 180 & 12.8 \\
\hline & No & 1231 & 87.2 \\
\hline \multirow[t]{2}{*}{ Hypercholesterolemia } & Yes & 187 & 13.3 \\
\hline & No & 1224 & 86.7 \\
\hline \multirow[t]{2}{*}{ Respiratory disorder } & Yes & 56 & 4 \\
\hline & No & 1355 & 96 \\
\hline \multirow[t]{2}{*}{ Renal disorder } & Yes & 19 & 1.3 \\
\hline & No & 1392 & 98.7 \\
\hline \multirow[t]{2}{*}{ Heart disease } & Yes & 28 & 2 \\
\hline & No & 1383 & 98 \\
\hline \multirow[t]{2}{*}{ Cancer } & Yes & 8 & 0.6 \\
\hline & No & 1403 & 99.4 \\
\hline \multicolumn{4}{|c|}{ Source of information regarding COVID-19 } \\
\hline \multirow[t]{2}{*}{ Social media } & Yes & 1375 & 97.4 \\
\hline & No & 36 & 2.6 \\
\hline \multirow[t]{2}{*}{ Mass media } & Yes & 1327 & 94 \\
\hline & No & 84 & 6 \\
\hline \multirow[t]{2}{*}{ Healthcare worker } & Yes & 844 & 59.8 \\
\hline & No & 567 & 40.4 \\
\hline \multirow[t]{2}{*}{ Others (family, friend, neighbour etc.) } & Yes & 1119 & 79.3 \\
\hline & No & 292 & 20.7 \\
\hline \multicolumn{4}{|l|}{ Acceptance of the COVID-19 vaccine } \\
\hline \multirow[t]{2}{*}{ Acceptance } & Yes & 1175 & 83.3 \\
\hline & No & 236 & 16.7 \\
\hline \multicolumn{4}{|c|}{ Concerns regarding the COVID-19 vaccine } \\
\hline \multirow[t]{2}{*}{ Lack of information } & Yes & 191 & 80.9 \\
\hline & No & 45 & 19.1 \\
\hline \multirow[t]{2}{*}{ Side effects } & Yes & 226 & 95.8 \\
\hline & No & 10 & 4.2 \\
\hline \multirow[t]{2}{*}{ Not safe } & Yes & 200 & 84.7 \\
\hline & No & 36 & 15.3 \\
\hline \multirow[t]{2}{*}{ Not effective } & Yes & 150 & 63.6 \\
\hline & No & 86 & 36.4 \\
\hline \multirow[t]{2}{*}{ COVID-19 is not dangerous } & Yes & 53 & 22.5 \\
\hline & No & 183 & 77.5 \\
\hline \multirow[t]{2}{*}{ Fear of injection } & Yes & 38 & 16.1 \\
\hline & No & 198 & 83.9 \\
\hline \multirow[t]{2}{*}{ Against vaccines in general } & Yes & 66 & 28 \\
\hline & No & 170 & 72 \\
\hline \multirow[t]{2}{*}{ Religious reasons } & Yes & 49 & 20.8 \\
\hline & No & 187 & 79.2 \\
\hline
\end{tabular}


Table 2 Medical illnesses, source of information, acceptance and concerns regarding COVID-19 vaccine among respondents ( $N=$ 1411) (Continued)

\begin{tabular}{llll}
\hline Medical illnesses & & $\boldsymbol{n}$ & \% \\
\hline Cultural reasons & Yes & 16 & 6.8 \\
& No & 220 & 93.2 \\
Believe in traditional remedies & Yes & 42 & 17.8 \\
& No & 194 & 82.2 \\
\hline
\end{tabular}

respondents aged 30 to 59 who were twice as likely to hesitate when compared to the youngest group of respondents aged 18 to 29 years. This finding contrasts to those of Robertson et al., who found that UK residents aged 25 to 34 years were more hesitant to take the vaccine compared to those aged 45 to 54 years [20]. Our findings also indicate that Buddhists are twice as likely to hesitate than Muslims. Recent studies among UK and US citizens have not shown the significance of religion as a predictor of vaccine hesitancy [20,21]. Additionally, respondents who resided in the East Coast Zone of Peninsular Malaysia and Sabah \& WP Labuan were twice as likely to hesitate than respondents who resided in Sarawak. Notably, a recent local study did not investigate residency across different states in Malaysia as a predictor of vaccine hesitancy [22]. Any interpretation of these findings should consider the sociodemographic characteristics of respondents, as the sample was predominantly comprised of Sarawakians, Malays and Muslims.

It was expected that the majority of the respondents would be from younger age groups, and, indeed, only $5.8 \%$ were from the elderly population. This could be due to the sampling method and how the questionnaire was circulated, as the elder age group might have limited access to smartphones and the internet. In the occupation group, students were more accepting compared with those working in medical and health occupations. This finding was different from the Indonesia study that

Table 3 Relative Important Index (RII) for concerns regarding COVID-19 vaccine among hesitant respondents $(n=236)$

\begin{tabular}{lll}
\hline Item & Concerns regarding COVID-19 vaccine & RII \\
\hline 1 & Lack of information & 0.90 \\
2 & Side effects & 0.98 \\
3 & Not safe & 0.92 \\
4 & Not effective & 0.82 \\
5 & CoVID-19 is not dangerous & 0.61 \\
6 & Fear of injection & 0.58 \\
7 & Against vaccines in general & 0.64 \\
8 & Religious reasons & 0.60 \\
9 & Cultural reasons & 0.53 \\
10 & Believe in traditional remedies & 0.59 \\
\hline
\end{tabular}

showed HCWs were twice likely to accept the COVID19 vaccine [15]. Although this study did not evaluate factors influencing COVID-19 vaccine acceptance, it is hypothesised that the reasons for potential acceptance are similar to those in other parts of the world, namely when the vaccine is generally available, if it is recommended by the employer and confidence in the development and safety of the vaccine $[14,23]$.

In a study conducted by researchers from the Institute of Clinical Research in July 2020 (before the availability of the COVID-19 vaccine), the vaccine's acceptance rate was much higher at $93.2 \%$, whereas the refusal rate was only $6.8 \%$ [24]. Factors that predicted COVID-19 vaccine acceptance were perception of the COVID-19 situation, COVID-19 as a threat to health and the susceptibility to infection. Notably, the acceptance rate was lower in the current study despite the knowledge that the vaccine is already developed and waiting to be available in Malaysia. A recent non-peer-reviewed survey done among 212,000 Malaysians had a much lower acceptance rate at only $67 \%$ [25].

Herd immunity is also known as 'population immunity'. For herd immunity to occur, the population coverage required through vaccination varies across diseases and is dependent on the basic reproduction number $\left(R_{0}\right)$, vaccine efficacy and duration of immunity $[26,27]$. The proportion of the population that must be vaccinated against COVID-19 to begin inducing herd immunity is unknown [28]. Thus, the challenge to determine the sufficient proportion of the population to create such immunity by mass vaccination remains. Nevertheless, the larger the number of vaccinated individuals, the better the immune coverage. Experts in Malaysia estimated that the proportion of the population that would need to be vaccinated might be as high as 80 to $90 \%$, as the $R_{0}$ number for some of the clusters in the current third wave seems to be relatively high [29].

Vaccine hesitancy was named as one of the top 10 threats to global health by the WHO in 2019. This was in response to a reduction in global immunisation rates for the measles, mumps and rubella vaccine, which slipped to $85 \%$ compared to the required target of $95 \%$ and led to numerous measles outbreaks [30]. The reluctance and refusal of the COVID-19 vaccine is a global problem. Furthermore, to have a substantial population 
Table 4 Factors associated with COVID-19 vaccine hesitance among respondents $(N=1411)$

\begin{tabular}{llll}
\hline Variable & $\boldsymbol{n}$ & Acceptance $\boldsymbol{n}(\%)$ & Hesitance $\boldsymbol{n}(\%)$ \\
\hline Age (year) & & & $67(11.7)$ \\
$18-29$ & 574 & $507(88.3)$ & $58(17)$ \\
$30-39$ & 341 & $283(83)$ & $47(19.1)$ \\
$40-49$ & 246 & $199(80.9)$ & $34(20.2)$ \\
$50-59$ & 168 & $134(79.8)$ & $30(36.6)$ \\
60 and above & 82 & $52(63.4)$ & \\
Gender & & & $90(17.1)$ \\
Male & 525 & $435(82.9)$ & $146(16.5)$ \\
Female & 886 & $740(83.5)$ & .747
\end{tabular}

\section{Race}

Malay
Chinese
Indian
Iban
Bidayuh
Melanau
Orang Ulu
Kadazan
Dusun
Other Indigenous \& Non-Malaysian

Religion

Islam

Christianity

886

740 (83.5)

.025

Buddhism

901

159

$763(84.7)$

$138(15.3)$

$126(79.2)$

33 (20.8)

31 (72.1)

$12(27.9)$

72 (92.3)

$6(7.7)$

47 (83.9)

9 (16.1)

40 (87)

6 (13)

$22(75.9)$

7 (24.1)

16 (69.6)

7 (30.4)

$17(73.9)$

6 (26.1)

41 (77.4)

$12(22.6)$

Other

$857(84)$

Marital Status

Single

228 (84.1)

163 (16)

271

80

$61(76.3)$

43 (15.9)

19 (23.8)

40

$29(72.5)$

$11(27.5)$

Married

$540(87.9)$

.001

Divorced

594 (79.6)

$74(12.1)$

$24(77.4)$

$152(20.4)$

Widow/Widower

$17(85)$

7 (22.6)

$3(15)$

\section{Education}

Less than tertiary

Tertiary education

$155(83.8)$

$1020(83.2)$

\section{Occupation}

Medical \& Health

Education

Security \& Defence

Industrial \&

Manufacturing

Construction

Management \& Administrative

Services

Student

Pensioner

\section{0}

234

31

63

31

141

119

358

82
177 (80.5)

$188(80.3)$

27 (87.1)

55 (87.3)

25 (80.6)

123 (87.2)

$96(80.7)$

324 (90.5)

53 (64.6)
$30(16.2)$

206 (16.8)

.842

43 (19.5)

46 (19.7)

4 (12.9)

8 (12.7)

6 (19.4)

$18(12.8)$

$23(19.3)$

34 (9.5)

$29(35.4)$ 
Table 4 Factors associated with COVID-19 vaccine hesitance among respondents ( $N=1411$ ) (Continued)

\begin{tabular}{l} 
Variable \\
\hline Unemployed \\
Other \\
Monthly Income (RM) \\
0-1200 \\
1201-4000 \\
4001-8000 \\
$>8000$
\end{tabular}

Current Residence

Sarawak
Sabah \& WP Labuan
Northern Zone*
Middle Zone*
Southern Zone*
East Coast Zone*

Diabetes Mellitus

No
Yes
Hypertension
No
Yes

\section{Hypercholesterolemia}

No

Yes

Respiratory Disorder

$$
\text { No }
$$$$
\text { Yes }
$$

Renal Disorder

$$
\text { No }
$$$$
\text { Yes }
$$

Heart Disease

$$
\text { No }
$$

Yes

Cancer

$$
\text { No }
$$

Yes

Social Media

$$
\text { No }
$$$$
\text { Yes }
$$

Mass Media

$$
\text { No }
$$$$
\text { Yes }
$$

Healthcare Workers

$$
\text { No }
$$$$
\text { Yes }
$$

Acceptance
$82(82.8)$
$25(75.8)$

$434(86.6)$
$297(83.4)$
$282(79.7)$
$162(81)$

$578(84.1)$

$578(84.1)$

75 (73.5)

97 (82.2)

289 (86)

99 (84.6)

37 (72.5)

1102 (83.9)

73 (75.3)

1032 (83.8)

143 (79.4)

180

1224

187

1355

56

1392

19

1383

28

1403

8

36

1375

84

1327

567

844

$144(77)$

1132 (83.5)

43 (76.8)

1160 (83.3)

15 (78.9)

1154 (83.4)

21 (75)

$1168(83.3)$

7 (87.5)

26 (72.2)

1149 (83.6)

69 (82.1)

$1106(83.3)$

472 (83.2)

703 (83.3)

$17(17.2)$
$8(24.2)$
$67(13.4)$
$59(16.6)$
$72(20.3)$
$38(19)$

Hesitance $\boldsymbol{n}(\%)$

$P$ value $^{\mathrm{a}}$

.044

.018

109 (15.8)

$27(26.5)$

$21(17.8)$

47 (14)

18 (15.4)

$14(27.5)$

.028

$212(16.1)$

$24(24.7)$

199 (16.2)

37 (20.6)
$1031(84.2) \quad 193(15.8)$

.184

$.543^{b}$

$.301^{\mathrm{b}}$

$1^{b}$

.072

.774

$15(17.9)$

$221(16.7)$

95 (16.8)

$141(16.7)$

.014

84

$223(16.5)$

$232(16.7)$

$4(21.1)$

229 (16.6)

7 (25)

235 (16.7)

1 (12.5)

$10(27.8)$

226 (16.4) 
Table 4 Factors associated with COVID-19 vaccine hesitance among respondents $(N=1411)$ (Continued)

\begin{tabular}{llll}
\hline Variable & $\boldsymbol{n}$ & Acceptance $\boldsymbol{n}(\%)$ & Hesitance $\boldsymbol{n}$ (\%) \\
\hline Friends, family, etc. & & & \\
No & 292 & $245(83.9)$ & $47(16.1)$ \\
Yes & 1119 & $930(83.1)$ & $189(16.9)$
\end{tabular}

${ }^{\mathrm{a}}$ Chi-square test for independence ${ }^{\mathrm{b}}$ Fisher's exact test

*Northern Zone: Kedah, Perak, Pulau Pinang, Perlis

*Middle Zone: Selangor, WP Kuala Lumpur, WP Putrajaya

*Southern Zone: Negeri Sembilan, Melaka, Johor

*East Coast Zone: Kelantan, Terengganu, Pahang

immunised to achieve herd immunity, reasons for vaccine hesitancy must be addressed. In this study, the rate for COVID-19 vaccine hesitance was $16.7 \%$ among 1411 respondents.

The leading cause for hesitancy was fear of the side effects of the vaccine (95.8\%), concerns about the safety (84.7\%), lack of information (80.9\%) and questions about the effectiveness of a new vaccine (63.6\%). Further analysis using the RII supported that side effects, safety, lack of information and effectiveness were the crucial concerns among respondents. This finding is similar to studies conducted in other countries that identified concerns over vaccine safety, potential side effects and effectiveness $[15,17]$.

Public confidence in vaccination to prevent infection may be affected by perceived risks associated with

Table 5 Predictors of COVID-19 vaccine hesitance among respondents $(N=1411)$

\begin{tabular}{|c|c|c|c|c|}
\hline & Crude OR & Adj. $O R$ & $(95 \% \mathrm{Cl} O R)$ & $P$ value $^{a}$ \\
\hline \multicolumn{5}{|l|}{ Age (years) } \\
\hline \multicolumn{5}{|l|}{$18-29$} \\
\hline $30-39$ & 1.55 & 1.60 & $1.09,2.36$ & .017 \\
\hline $40-49$ & 1.79 & 1.99 & $1.31,3.02$ & .001 \\
\hline $50-59$ & 1.92 & 2.04 & $1.28,3.23$ & .003 \\
\hline 60 and above & 4.37 & 5.22 & $3.06,8.90$ & $<.001$ \\
\hline \multicolumn{5}{|l|}{ Religion } \\
\hline Islam & 1.00 & 1.00 & & \\
\hline Christianity & 0.99 & 1.08 & $0.73,1.60$ & .700 \\
\hline Buddhism & 1.64 & 2.01 & $1.15,3.53$ & .015 \\
\hline Other & 1.99 & 2.67 & $1.26,5.64$ & .010 \\
\hline \multicolumn{5}{|l|}{ Current Residence } \\
\hline Sarawak & 1.00 & 1.00 & & \\
\hline Sabah \& WP Labuan & 1.91 & 2.22 & $1.35,3.66$ & .002 \\
\hline Northern Zone* & 1.15 & 1.07 & $0.62,1.83$ & .812 \\
\hline Middle Zone* & 0.86 & 0.82 & $0.55,1.21$ & .308 \\
\hline Southern Zone* & 0.96 & 1.01 & $0.57,1.77$ & .985 \\
\hline East Coast Zone* & 2.01 & 2.55 & $1.30,5.01$ & .007 \\
\hline
\end{tabular}

Adj. OR Adjusted odds ratio

*Northern Zone: Kedah, Perak, Pulau Pinang, Perlis

*Middle Zone: Selangor, WP Kuala Lumpur, WP Putrajaya

*Southern Zone: Negeri Sembilan, Melaka, Johor

*East Coast Zone: Kelantan, Terengganu, Pahang vaccination. This was reflected in the hesitant group, in which $95.8 \%$ reported a fear of vaccine side effects as a reason for their refusal. With the COVID-19 vaccine and ongoing trials, the most common side effects reported were pain at the injection site, tiredness, headache, muscle pain, chills, joint pain, and fever, which typically would last for several days [31]. These side effects were noted more common after the second dose on vaccine trials. Although severe side effects, such as anaphylaxis, may occur, these are rare [32]. However, the risks of contracting COVID-19 infection, which may lead to severe complications, outweigh the risks of getting the vaccine.

Other reasons for the COVID-19 vaccine hesitance were being against vaccines in general $(28 \%)$, the perception that COVID-19 is not dangerous $(22.5 \%)$, religious reasons $(20.8 \%)$, belief in traditional remedies (17.8\%), fear of injection (16.1\%) and cultural reasons (6.8\%). Similar findings are seen in the studies conducted in Europe [17]. The reason for vaccine hesitancy is usually due to a lack of trust in the health care professionals and the government to choose an alternative or complementary medicine for their treatment, which cannot replace the vaccine function [33]. Although the number of those against the vaccine, in general, has been relatively small, their opposing view on vaccines must be acknowledged because they may influence others, especially those undecided but aware of the risks of the vaccine [34].

When discussing vaccine hesitancy or refusal, one cannot ignore conspiracy theories. Conspiracy theories increase in times of crisis when people feel threatened, uncertain and insecure - much like the situation created by the COVID-19 pandemic [35]. Anti-vaccine conspiracy theories appear to reduce vaccination intentions by inducing undue concerns about the dangers of vaccines and increasing feelings of powerlessness, disillusionment and mistrust in authorities [36]. Thus, effective measures to reduce the negative impact of conspiracy theories must be implemented. These include having an ethical and responsible mass media with media regulatory authorities on statement guidelines regarding the COVID19 pandemic, addressing religious elements surrounding the conspiracy theories, stern measures from the 
healthcare authorities and increasing awareness on COVID-19 to reduce negative perceptions among the general community [37].

In this study, the respondents' source of information about COVID-19 was mainly from social media (97.4\%) and mass media (94.0\%). Many reliable websites are providing the public with updates regarding this disease, including information about the vaccines, namely the WHO, Centers for Disease Control and Prevention (CDC) and the Ministry of Health $(\mathrm{MOH})$ [38-40]. Information about this pandemic is also regularly aired across radio, television networks and newspapers, and thus it is quite worrying that $80.9 \%$ of the respondents stated that they lacked information about the COVID-19 vaccine. With the robust information available, it can be too overwhelming for the general population. Thus, further intervention needs to be done to convey the relevant health education to enable good knowledge transfer resulting in increased awareness to make informed choices.

Although the acceptance of the COVID-19 vaccine in this study was relatively high, the actual willingness to vaccinate will only be known once the vaccine arrives in Malaysia. As for now, the measures to prevent infection via wearing face masks, physical distancing, proper handwashing and avoidance of crowded and small confined spaces must be emphasised at all times.

\section{Limitations of the study}

Data collection occurred online, which means we may not have reached vulnerable groups, including those with lower socioeconomic background and those who are illiterate. Also, a larger percentage of the respondents were from a single geographic area, which may impact the generalisation of the survey results.

\section{Conclusions}

The acceptance rate of the COVID-19 vaccine among the Malaysian population who participated in this study was high. This corresponds to other studies conducted with Asian and Western populations. The Malaysian government and other related agencies must target their campaign to address the concerns reported here about the vaccine and prepare to implement the mass immunisation programme for COVID-19 for Malaysian citizens. In implementing the nationwide COVID-19 vaccination programme, researchers must continue to investigate vaccine hesitancy and health education must be prepared to address any concerns that may arise during the programme.

\section{Abbreviations}

$\%$ : Percentage; CDC: Centers of Disease Control and Prevention;

$\mathrm{Cl}$ : Confidence interval; COVID-19: Corona virus disease 2019; MOH: Ministry of Health; OR: Odds ratio; P-Value: Probability value; WHO: World Health Organization

\section{Supplementary Information}

The online version contains supplementary material available at https://doi. org/10.1186/s12889-021-11071-6.

Additional file 1 Appendix 1. Questionnaire (English version). Appendix 2. Questionnaire (Bahasa Melayu version).

\section{Acknowledgements}

The authors would like to thank all of the respondents for participating in the survey.

\section{Authors' contributions}

SASAR, RE, JO, BIB contributed to the conception and design of all stages of the study. RE, SASAR, JO, BIB contributed to data collection. RE, SASAR, JO,

$Z A, B I B, L S$ conducted the study analyses. All authors read and approved the final manuscript.

\section{Funding}

This research was self-funded. Open Access funding provided by Universiti Malaysia Sarawak.

\section{Availability of data and materials}

The datasets used and analysed during the current study are available from the corresponding author on reasonable request.

\section{Declarations}

Ethics approval and consent to participate

The study was approved by the Research and Ethics Committee, Faculty of Medicine and Health Sciences, Universiti Malaysia Sarawak (approval reference: NO RUJUKAN ETIKA FME/21/40).

Informed consents were taken from all eligible participants before they attempted the questionnaire.

\section{Consent for publication}

Not applicable.

\section{Competing interests}

The authors declare that they have no competing interests.

Received: 16 February 2021 Accepted: 12 May 2021

Published online: 12 June 2021

\section{References}

1. World Health Organization. WHO Coronavirus Disease (COVID-19) Dashboard. Available from: https://covid19.who.int/?gclid=EAlalQobChMI2_ CM6eDZ6gIVghh9Ch3nDQm1EAAYASAAEgLqwPD_BwE. Accessed 15 Feb 2021.

2. World Health Organization. COVID-19 Situation in WHO Western Pacific Region. Available from: https://www.who.int/westernpacific/emergencies/ covid-19/situation-reports. Accessed 15 Feb 2021.

3. Chakraborty C, Sharma A, Bhattacharya M, Sharma G, Lee SS. The 2019 novel coronavirus disease (COVID-19) pandemic: a zoonotic prospective. Asian Pac J Trop Med. 2020;13(6):242-6. https://doi.org/10.4103/1995-7645.2 81613.

4. Chakraborty C, Sharma R, Sharma G, Bhattacharya M. Extensive partnership, collaboration, and teamwork is required to stop the COVID-19 outbreak. Arch Med Res. 2020;51(7):728-30. https://doi.org/10.1016/j.arcmed.2020.05. 021.

5. Huang C, Wang Y, Li X, Ren L, Zhao J, Hu Y, et al. Clinical features of patients infected with 2019 novel coronavirus in Wuhan, China. Lancet. 2020;395(February 15):497-506. https://doi.org/10.1016/S0140-6736(20)301 83-5.

6. Guan W, Ni Z, Hu Y, Liang W, Ou C, He J, et al. Clinical characteristics of coronavirus disease 2019 in China. N Engl J Med. 2020;382(18):1708-20. https://doi.org/10.1056/NEJMoa2002032.

7. Chen N, Zhou M, Dong X, Qu J, Gong F, Han Y, et al. Epidemiological and clinical characteristics of 99 cases of 2019 novel coronavirus pneumonia in Wuhan, China: a descriptive study. Lancet. 2020;395(10223):507-13 Available from: https://doi.org/10.1016/S0140-6736(20)30211-7. 
8. Polack FP, Thomas SJ, Kitchin N, Absalon J, Gurtman A, Lockhart S, et al. Safety and efficacy of the BNT162b2 mRNA Covid-19 vaccine. N Engl J Med. 2020;383(27):2603-15. https://doi.org/10.1056/NEJMoa2034577.

9. Koven S. Emergency Use Authorization of Covid Vaccines-Safety and Efficacy Follow-up Considerations. N Engl J Med. 2020;393(19):e107(1-3). Available from: nejm.org

10. Ledford H, Cyranoski D, Van Noorden R. The UK has approved a COVID vaccine - here's what scientists now want to know. Nature. 2020;588(7837): 205-6. https://doi.org/10.1038/d41586-020-03441-8.

11. Cohen J. First vaccine may stymie hunt for better ones. Science (80- ). 2020; 23(370):389-90.

12. No, we are not paying 20 times more, says Khairy. Available from: https:// www.freemalaysiatoday.com/category/nation/2020/12/21/no-we-are-not-pa ying-20-times-more-says-khairy/. Accessed 3 Jan 2021.

13. Malik AA, McFadden SAM, Elharake J, Omer SB. Determinants of COVID-19 vaccine acceptance in the US. EClinicalMedicine. 2020;26:100495 Available from: https://doi.org/10.1016/j.eclinm.2020.100495.

14. Lazarus J V., Ratzan SC, Palayew A, Gostin LO, Larson HJ, Rabin K, et al. A global survey of potential acceptance of a COVID-19 vaccine. Nat Med. 2020; Available from: https://doi.org/10.1038/s41591-020-1124-9

15. Harapan H, Wagner AL, Yufika A, Winardi W, Anwar S, Gan AK, et al. Acceptance of a COVID-19 vaccine in Southeast Asia: a cross-sectional study in Indonesia. Front Public Heal. 2020;8(July):1-8.

16. Wang J, Jing R, Lai $X$, Zhang H, Lyu $Y$, Knoll MD, et al. Acceptance of covid19 vaccination during the covid-19 pandemic in China. Vaccines. 2020; 8(482):1-14

17. Neumann-Böhme S, Varghese NE, Sabat I, Barros PP, Brouwer W, van Exel J, et al. Once we have it, will we use it? A European survey on willingness to be vaccinated against COVID-19. Eur J Heal Econ. 2020;21(7):977-82 Available from: https://doi.org/10.1007/s10198-020-01208-6.

18. Al-Mohaithef M, Padhi BK. Determinants of COVID-19 vaccine acceptance in Saudi Arabia: a web-based National Survey. J Multidiscip Healthc. 2020;13: 1657-63. https://doi.org/10.2147/JMDH.S276771.

19. Echoru I, Ajambo PD, Bukenya EM. Acceptance and Risk Perception of COVID-19 Vaccine in Uganda: A Cross Sectional Study in Western Uganda. Res Sq. 2020;1-11. Available from: https://doi.org/10.21203/rs.3.rs-78780/v1

20. Robertson E, Reeve KS, Niedzwiedz CL, Moore J, Blake M, Green M, et al. Predictors of COVID-19 vaccine hesitancy in the UK household longitudinal study. Brain Behav Immun. 2021;94(January):41-50 Available from: https:// doi.org/10.1016/j.bbi.2021.03.008

21. Khubchandani J, Sharma S, Price JH, Wiblishauser MJ, Sharma M, Webb FJ. COVID-19 vaccination hesitancy in the United States: a rapid National Assessment. J Community Health. 2021;46(2):270-7. Available from: https:// doi.org/10.1007/s10900-020-00958-x.

22. Musa AF, Soni T, Cheong XP, Bin NR. Vaccine hesitancy among parents in Kuala Lumpur: a single center study. F1000Research. 2020;8(September): 1653.

23. Funk C, Tyson A. Intent to Get a COVID-19 Vaccine Rises to $60 \%$ as Confidence in Research and Development Process Increases. Pew Res Cent. 2020;(December):1-29. Available from: https://www.pewresearch.org/ science/2020/12/03/intent-to-get-a-covid-19-vaccine-rises-to-60-asconfidence-in-research-and-development-process-increases/

24. June LFW, Leong CT, Teh HS, Woon YL. Internet]2020. Factors influencing acceptance of COVID-19 vaccination among Malaysian adults. https://doi. org/10.5281/zenodo.4019910.

25. Kementerian Kesihatan Malaysia. KKMalaysia on Twitter:"Hasil tinjauan vaksin \#COVID19: Terima atau tolak?. Available from: https://twitter.com/kkmputraja ya/status/1344580831206023169?lang=en. Accessed 31 Dec 2020.

26. Dodd RH, Cvejic E, Bonner C, Pickles K, McCaffery K, Ayre J, et al. Willingness to vaccinate against COVID-19 in Australia. Lancet Infect Dis. 2021;21(3):318-9. https://doi.org/10.1016/S1473-3099(20)30559-4.

27. M Anderson R, Vegvari C, Truscott J, S Collyer B. Challenges in creating herd immunity to SARS-CoV-2 infection by mass vaccination. Lancet. 2020; 396(November):1614-1616, DOI: https://doi.org/10.1016/S0140-6736(20)3231 8-7.

28. World Health Organization. Coronavirus disease (COVID-19): Herd immunity, lockdowns and COVID-19. 2020. Available from: https://www.who.int/newsroom/q-a-detail/herd-immunity-lockdowns-and-covid-19

29. Experts: Majority ready to accept Covid-19 vaccine but more awareness needed. Available from: https://www.thestar.com.my/news/nation/2021/01/ 08/experts-majority-ready-to-accept-covid-19-vaccine-but-more-awarenessneeded. Accessed 12 Jan 2012.

30. Megget K. Even covid-19 can't kill the anti-vaccination movement. BMJ. 2020;369(June):1-2 Available from: https://doi.org/10.1136/bmj.m2184

31. World Health Organization. Status of COVID-19 Vaccines within WHO EUL/ PQ evaluation process. 2021. Available from: https://extranet.who.int/ pqweb/sites/default/files/documents/Status_COVID_VAX_20Jan2021_v2. pdf. Accessed 23 Jan 2021.

32. Centers for Disease Control and Prevention. What to Expect after Getting a COVID-19 Vaccine. 2021

33. Taib WRW, Yusoff NAM, Hussin TMAR, Ahmad A. Issues in vaccine hesitancy in Malaysia: a countering approach. J Biomed Clin Sci. 2017;2(1):42-6 Available from: http://apps.amdi.usm.my/journal/.

34. Burki T. The online anti-vaccine movement in the age of COVID-19. Lancet Digit Heal [Internet]. 2020;2(10):e504-5 Available from: https://doi.org/10.101 6/S2589-7500(20)30227-2.

35. Douglas KM. COVID-19 conspiracy theories. Gr Process Intergr Relations. 2021;24(2):270-5. https://doi.org/10.1177/1368430220982068.

36. Jolley D, Douglas KM. The effects of anti-vaccine conspiracy theories on vaccination intentions. PLoS One. 2014;9(2):e89177. https://doi.org/10.1371/ journal.pone.0089177.

37. Khan $\mathrm{YH}$, Mallhi TH, Alotaibi NH, Alzarea Al, Alanazi AS, Tanveer $\mathrm{N}$, et al. Threat of COVID-19 vaccine hesitancy in Pakistan: the need for measures to neutralize misleading narratives. Am J Trop Med Hyg. 2020;103(2):603-4. https://doi.org/10.4269/ajtmh.20-0654.

38. World Health Organization. Coronavirus (COVID-19) in Malaysia. Information for the public. Available from: https://www.who.int/malaysia/emergencies/ covid-19-in-malaysia/information. Accessed 15 Jan 2021.

39. Centers for Disease Control and Prevention. COVID-19. Available from: https://www.cdc.gov/coronavirus/2019-ncov/index.html. Accessed 15 Jan 2021.

40. Kementerian Kesihatan Malaysia. COVID-19 Malaysia. Available from: http:// covid-19.moh.gov.my/. Accessed 15 Jan 2021.

\section{Publisher's Note}

Springer Nature remains neutral with regard to jurisdictional claims in published maps and institutional affiliations.

\section{Ready to submit your research? Choose BMC and benefit from:}

- fast, convenient online submission

- thorough peer review by experienced researchers in your field

- rapid publication on acceptance

- support for research data, including large and complex data types

- gold Open Access which fosters wider collaboration and increased citations

- maximum visibility for your research: over $100 \mathrm{M}$ website views per year

At BMC, research is always in progress.

Learn more biomedcentral.com/submissions 